\title{
Synthesis and Antiproliferative Activities of Triphenylmethanol Conjugates of Leuprorelin
}

\author{
Ryan Beni*, William Boadi, Kaleh Karim, Jawzah Alnakhli, Samiyah Alhamed \\ Department of Chemistry, Tennessee State University, Nashville, TN, USA \\ Email: *rbeni@tnstate.edu, wboadi@tnstate.edu, kkarim@my.tnstate.edu, al.anwar.2008@hotmail.com, \\ sosoalzaben2@gmail.com
}

How to cite this paper: Beni, R., Boadi, W., Karim, K., Alnakhli, J. and Alhamed, S. (2019) Synthesis and Antiproliferative Activities of Triphenylmethanol Conjugates of Leuprorelin. Open Journal of Medicinal Chemistry, 9, 37-47.

https://doi.org/10.4236/ojmc.2019.92002

Received: March 19, 2019

Accepted: June 7, 2019

Published: June 10, 2019

Copyright (C) 2019 by author(s) and Scientific Research Publishing Inc. This work is licensed under the Creative Commons Attribution International License (CC BY 4.0).

http://creativecommons.org/licenses/by/4.0/

\begin{abstract}
Leuprorelin $^{\circledR}$ (LEP) is an FDA drug for breast cancer and prostate cancer treatment. There are several reported adverse effects such as transient hypertension, excessive salivation, and increased dysuria during treatment with LEP. In this study, the efficacy and toxicity of LEP were modified by using a drug delivery system to adjust the physicochemical properties. In this regard, Leuprorelin ${ }^{\circledR}$ conjugates of triphenylmethanol derivatives (TPMs) were synthesized as prodrugs. Comparative antiproliferative assays showed that LEP-TPMs conjugates had significantly higher antiproliferative activities than the corresponding non-covalent physical mixtures of the TPMs and LEP against human invasive ductal carcinoma (BT-549), human prostate carcinoma (PC3), human lung cancer (A549) and mouse pre-adipocytes (3T3-L1) cells.
\end{abstract}

\section{Keywords}

Prodrugs, Leuprorelin, Polyphenols, Prostate Cancer, Triphenylmethanol, Prodrugs

\section{Introduction}

Leuprorelin $^{\oplus}$ (LEP) is a synthetic analogue of the gonadotropin-releasing hormone $(\mathrm{GnRH})$, which was first approved by the FDA in 1985 to treat a range of sex hormone-related disorders such as precocious puberty, endometriosis, breast cancer and prostate cancer. The structure of LEP consists of nine amino acids (Pyr-His-Trp-Ser-Tyr-D-Leu-Leu-Arg-Pro-NHEt).

Initially, LEP stimulates the pituitary secretion of gonadotropins luteinizing hormone (LH) and follicle stimulating hormone (FSH). However, prolonged stimulation (constant concentration of LEP in the blood) of the pituitary gland 
causes insensitivity to the action of GnRH. This reduces the level of gonadotropin in the blood, resulting in decreased levels of sex hormones to post-castration or menopausal levels. These effects are reversible. In addition to the usual side effects of the GnRH agonists, other reported adverse effects include transient hypertension, dry mouth, excessive salivation, paraesthesia, and increased dysuria [1]. The direct antiproliferative activity of LEP on cancer cells and improving its delivery have not been investigated.

The efficacy and toxicity of anticancer drugs can be modified by using drug delivery systems and adjusting the physicochemical properties (such as lipophilicity, cellular uptake, and prolonging activity) through chemical conjugation with various chemical moieties. The prodrug strategy is a drug delivery system through which chemical conjugation with the parent drug [2] [3], has been widely used in the delivery of anticancer drugs such as Leuprorelin ${ }^{\otimes}$ and Doxorubicin $^{\circledR}$ [4] [5]. For example, several conjugation methods have been used to improve the delivery of Doxorubicin ${ }^{\oplus}$, including using gold nanoparticles [6], gold nanospheres [7], liposomes [8], peptides [9]-[14], and dendrimers [15]. However, the antiproliferative activity of LEP and its conjugation with agents who have optimal lipophilicity have not been previously reported. Herein, we investigated the anticancer activity and the development of prodrug conjugates of LEP and polyphenols to enhance the delivery of LEP.

Polyphenols are naturally occurring compounds found largely in fruits, vegetables, cereals, and beverages. Fruits like grapes, apples, pears, cherries, and berries contain up to $200-300 \mathrm{mg}$ of polyphenols per 100 grams fresh weight [16] [17] [18]. In the last decade, there has been increased interest in the potential health benefits of dietary plant polyphenols as antioxidants. The effect of polyphenols on human cancer cell lines is most often protective and induces a reduction in the number of tumors or the growth rate of tumors. These effects have been observed at various sites including the mouth, stomach, duodenum, colon, liver, lungs, mammary glands and skin. Many polyphenols, such as quercetin, catechins, isoflavones, lignans, flavanones, ellagic acid, red wine polyphenols, resveratrol, and curcumin have been tested; all of them showed protective effects in some models although their mechanisms of action were found to be different [19] [20]. Polyphenols influence the metabolism of pro-carcinogens by modulating the expression of cytochrome P450 enzymes involved in their activation of carcinogens [21] [22].

To take advantage of the anticancer properties of polyphenolic antioxidants, several polyphenolic derivatives were chosen for conjugation with LEP. Dodecanedioic acid was selected as a lipophilic linker to attach LEP to polyphenolic derivatives. In this study, we will first report the synthesis of the antioxidant triphenylmethanol (TPMs) derivatives of LEP through the covalent conjugation with dodecanedioic acid as the linker. Second, we will report the evaluation of their in vitro cell antiproliferative activities in multiple cell lines.

In order to study cell antiproliferative activities of LEP and LEP-TPM conju- 
gates compared to the corresponding physical mixtures, we selected three cancer cell lines: 1) human invasive ductal carcinoma (BT-549); 2) human prostate carcinoma (PC3) and 3) human lung cancer (A549). Obesity is a serious problem which heightens the risk of several chronic illnesses including cancer development [23] [24] [25] [26]. It has been estimated that about $20 \%$ of all cancers are caused by excess weight [27]. In addition to studying cancer cell lines, we also studied the anti-obesity effect of our synthesized compounds in obese mouse pre-adipocyte fibroblast cells 3T3-L1 cells.

\section{Experimental}

\subsection{Preparation of TPMs 1a-e}

The TPMs were synthesized using a modified method based on procedures identified in the literature [28] [29] (Figure 1). Accordingly, 1,3,5-trioxane (15 mmole) was added to anisole, 2-fluoroanisole, 2-methylanisole, 1,2-dimethoxybenzene or methyl 2-methoxybenzoate (100 mmole) in $10 \mathrm{~mL}$ glacial acetic acid. The mixture was heated to $90^{\circ} \mathrm{C}-95^{\circ} \mathrm{C}$, then $1 \mathrm{~mL}$ of sulfuric acid: glacial acetic acid (1:5, $\mathrm{v} / \mathrm{v}$ ) was added to the solution. The mixture was stirred for 5 hours at $90^{\circ} \mathrm{C}-95^{\circ} \mathrm{C}$. The reaction mixture was then cooled to $0^{\circ} \mathrm{C}$ using an ice bath and a homogenous solution of sodium nitrite (1.0 g, $15 \mathrm{mmole})$ and anisole, 2-fluoroanisole, 2-methylanisole, 1,2-dimethoxybenzene or methyl 2-methoxybenzoate (15 mmole) in $10 \mathrm{~mL}$ concentrated sulfuric acid was added to the reaction mixture. The ice bath was removed and stirring continued at room temperature for an additional 24 hours. The mixture was then poured into crushed ice (100 g) while stirring. The precipitate was filtered off and dried under vacuum and further purified on $\mathrm{C}_{18}$ column and a gradient combination of hexanes/ethyl acetate as solvent (increasing the percentage of ethyl acetate from $0 \%$ to $60 \%$ during a course of 55 minutes) using a Teledyne CombiFlash ${ }^{\circledR}$ Rf-200 chromatography machine with the gradient system set at a constant flow rate of $25 \mathrm{ml} / \mathrm{min}$ to yield pure products in $61 \%-87 \%$ yield.

Tris(4-methoxyphenyl)methanol (1a), (3.50 g, 67\%), MS (ESI-TOF) (m/z) for $\mathrm{C}_{22} \mathrm{H}_{23} \mathrm{O}_{4}$ : calcd., 351.2, found $351.2[\mathrm{M}+\mathrm{H}]^{+}$; tris(3-fluoro-4-methoxyphenyl)methanol (1b), (3.65 g, 61\%), MS (ESI-TOF)

$(\mathrm{m} / \mathrm{z})$ for $\mathrm{C}_{22} \mathrm{H}_{20} \mathrm{~F}_{3} \mathrm{O}_{4}$ : calcd. 405.1, found $405.1[\mathrm{M}+\mathrm{H}]^{+}$;

tris(3-methyl-4-methoxyphenyl)methanol (1c), (4.77 g, 81\%), MS (ESI-TOF) $(\mathrm{m} / \mathrm{z})$ for $\mathrm{C}_{25} \mathrm{H}_{29} \mathrm{O}_{4}$ calcd. 393.2, found $393.2[\mathrm{M}+\mathrm{H}]^{+}$; tris(3,4-dimethoxyphenyl)methanol (1d), (5.75 g, 87\%), MS (ESI-TOF) (m/z) for $\mathrm{C}_{25} \mathrm{H}_{29} \mathrm{O}_{7}$ : calcd, 441.2, found $441.3[\mathrm{M}+\mathrm{H}]^{+}$;

trimethyl 5, 5', 5"-(hydroxymethanetriyl)tris(2-methoxybenzoate) (1e), (5.57 g, 77\%), MS (ESI-TOF) (m/z) for $\mathrm{C}_{28} \mathrm{H}_{29} \mathrm{O}_{10}$ : calcd. 525.2, found $525.2[\mathrm{M}+\mathrm{H}]^{+}$.

\subsection{Preparation of Tris(2-(Hydroxymethyl)Phenol) Conjugates of LEP 2a-e}

Tris(4-methoxyphenyl)methanol derivatives 1a-e (0.05 mmol), LEP acetate (0.05 mmol), dodecanedioic acid, $11.5 \mathrm{mg}, 0.05 \mathrm{mmol}$ ) and HBTU (19 mg, 0.05 


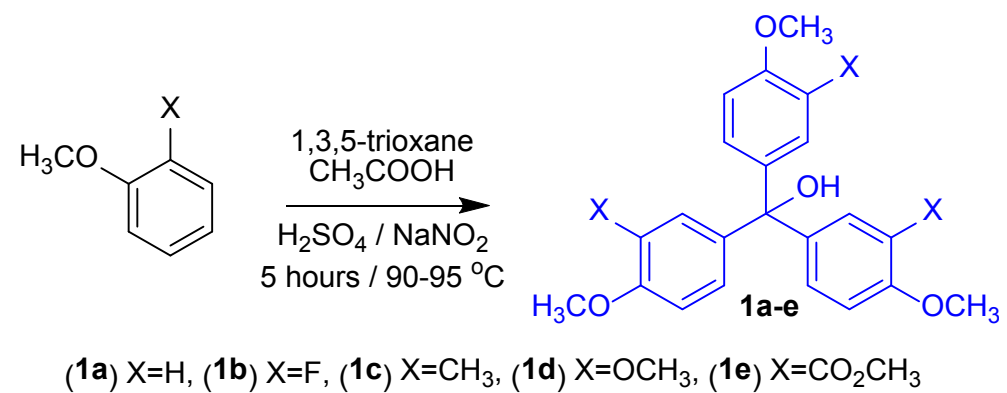

Figure 1. Preparation of triphenylmethanol (TPMs) derivatives 1a-e.

mmol) were dissolved in dry NMP ( $3 \mathrm{~mL}) . N, N^{\prime}$-diisopropyl carbodiimide (DIC, $8 \mu \mathrm{L}, 0.05 \mathrm{mmol}$ ) and $N, N$-Diisopropylethylamine (DIPEA, $21 \mu \mathrm{L}, 0.12 \mathrm{mmol}$ ) were added to the reaction mixture. The mixture was stirred at room temperature for 24 hours. Afterwards, the solvent was evaporated and dried under vacuum. The final product was purified on a $\mathrm{C}_{18}$ column and hexanes/ethyl acetate as solvents (increasing the percentage of ethyl acetate from $0 \%$ to $75 \%$ during a course of 60 minutes) using a TeledyneCombiFlash ${ }^{\circledR}$ Rf-200 chromatography machine. The gradient system was set at a constant flow rate of $25 \mathrm{ml} / \mathrm{min}$ to yield LEP-TPMs conjugates 2a-e (Figure 2). LEP-TPMs conjugate (2a), (63 mg, $68 \%)$, MS (ESI-TOF) (m/z) for $\mathrm{C}_{93} \mathrm{H}_{124} \mathrm{~N}_{16} \mathrm{O}_{18}$ : calcd, 1753.9358 , found 1753.9337 $[\mathrm{M}+\mathrm{H}]^{+}$; LEP-TPMs conjugate $(2 \mathrm{~b}),(63 \mathrm{mg}, 69 \%)$, MS (ESI-TOF) $(\mathrm{m} / \mathrm{z})$ for $\mathrm{C}_{93} \mathrm{H}_{122} \mathrm{~F}_{3} \mathrm{~N}_{16} \mathrm{O}_{18}$ : calcd, 1807.9075, found $1807.9087[\mathrm{M}+\mathrm{H}]^{+}$; LEP-TPMs conjugate (2c), (63 mg, 63\%), MS (ESI-TOF) (m/z) for $\mathrm{C}_{96} \mathrm{H}_{131} \mathrm{~N}_{16} \mathrm{O}_{18}$ : calcd, 1795.9827, found $1795.9821[\mathrm{M}+\mathrm{H}]^{+}$; LEP-TPMs conjugate (2d), (71 mg, 76\%), MS (ESI-TOF) $(\mathrm{m} / \mathrm{z})$ for $\mathrm{C}_{96} \mathrm{H}_{131} \mathrm{~N}_{16} \mathrm{O}_{21}$ : calcd, 1843.9675, found 1843.9667 $[\mathrm{M}+\mathrm{H}]^{+}$; LEP-TPMs conjugate $(2 \mathrm{e}),(78 \mathrm{mg}, 83 \%)$, MS (ESI-TOF) $(\mathrm{m} / \mathrm{z})$ for $\mathrm{C}_{99} \mathrm{H}_{131} \mathrm{~N}_{16} \mathrm{O}_{24}$ : calcd, 1927.9522, found $1927.9533[\mathrm{M}+\mathrm{H}]^{+}$.

\subsection{Cell Culture}

Human invasive ductal breast carcinoma (BT-549), human prostate carcinoma (PC3), human lung cancer (A549) and mouse pre-adipocytes (3T3-L1) cell lines were obtained from American Type Culture Collection. The cells were grown on $75 \mathrm{~cm}^{2}$ cell culture flasks in media consisting of $89 \%$ Dulbecco's Modified Eagle's Medium (DMEM) (GIBCO, Grand Island, NY) for pre adipocytes cell line and supplemented with $10 \%$ fetal bovine serum (FBS) and $1 \%$ penicillin-streptomycin solution $(10,000$ units of penicillin and $10 \mathrm{mg}$ of streptomycin in $0.9 \% \mathrm{NaCl})$ in a humidified atmosphere of $5 \% \mathrm{CO}_{2}, 95 \%$ air at $37^{\circ} \mathrm{C}$.

\subsection{Antiproliferative Assay}

Antiproliferative activities of synthesized LEP-TPMs 2a-e and physical mixtures of TPMs 1a-e + LEP were evaluated in BT-549, PC3, A549 and 3T3-L1 cells and the results were compared with that of LEP alone. The assay was carried out using Cell Titer 96 aqueous one solution cell proliferation assay kit (Promega, 

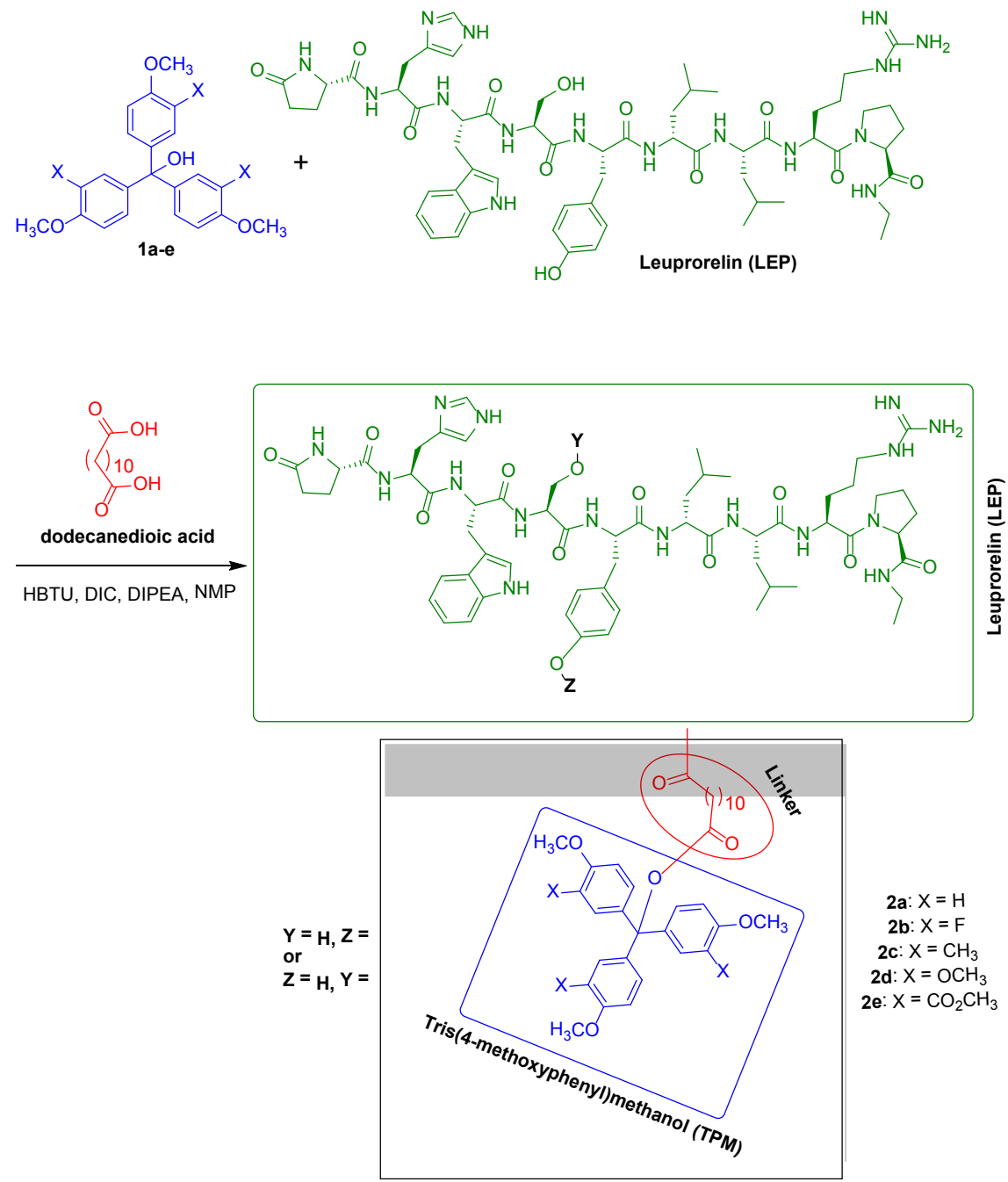

Figure 2. Synthesis of triphenylmethanol conjugates [30] of LEP 2a-e.

USA). Briefly upon reaching about $75 \%-80 \%$ confluency, the cells were suspended in 10,000 cells $/ \mathrm{mL}$ while $100 \mu \mathrm{L}$ of the cell suspensions were placed in each well of the 96 well culture plate. After seeding for 24 hours, the cells were treated with 5 - $100 \mu \mathrm{M}$ of compounds $2 \mathrm{a}-\mathbf{e}$ in $2 \%$ DMSO in triplicate. LEP (5 $100 \mu \mathrm{M})$ was used as the positive control. For the physical mixtures, an appropriate volume of LEP stock solution was mixed with an appropriate volume of an aqueous solution of compounds 1a-e physically to obtain a final concentration of TPMs and LEP (5 - $100 \mu \mathrm{M}$ each). The mixtures were vigorously mixed and vortexed until the solutions became homogeneous. Subsequently, the mixtures were incubated for $30 \mathrm{~min}$ at $37^{\circ} \mathrm{C}$ before adding to the cells. Incubation was carried out at $37^{\circ} \mathrm{C}$ in an incubator supplied with $5 \% \mathrm{CO}_{2}$ for $72 \mathrm{~h}$. At the end of the sample exposure period, $20 \mu \mathrm{L}$ Cell Titer 96 aqueous solution was added. The plate was returned to the incubator for 1 hour in a humidified atmosphere at $37^{\circ} \mathrm{C}$. The absorbance of the formazan product was measured at $490 \mathrm{~nm}$ using a microplate reader. The percentage of cell survival was calculated 
as the OD value of cells treated with the test compound-OD value of culture medium/(OD value of control cells-OD value of culture medium) $\times 100 \%$.

\subsection{Flow Cytometry}

Human prostate carcinoma (PC3) was treated with $25 \mu \mathrm{M}$ of LEP, 2b, 2c, and $2 \mathrm{e}$ for $1 \mathrm{~h}$ followed by $24 \mathrm{~h}$ incubation in drug-free medium. Cells were fixed in ice-cold ethanol: PBS (70:30, v/v) for $2 \mathrm{~h}$ at $4^{\circ} \mathrm{C}$, further resuspended in PBS with $100 \mu \mathrm{g} / \mathrm{mL}$ RNase and $40 \mu \mathrm{g} / \mathrm{mL}$ propidium iodide, and incubated at $37^{\circ} \mathrm{C}$ for 30 min. The DNA content (for 10,000 cells) was analyzed using a FACS instrument equipped with Flowjo software (Flowjo LLC, USA). The analyses of cell cycle distribution were performed in triplicate $(n=2$ plates per experiment) for the sample treatment. The coefficient of variation, according to Flowjo acquisition sotware, was always less than $5 \%$.

\section{Results and Discussion}

\subsection{Chemistry}

LEP, DMSO and other chemicals and reagents were purchased from Fisher Scientific or Sigma-Aldrich Chemical Co. All coupling reactions (Figure 2) were carried out in Bio-Rad polypropylene columns by shaking and mixing using a Glass $\mathrm{Col}^{\oplus}$ small tube rotator in dry conditions at room temperature. TPMs 1a-e which are the mimics of natural poly phenolic antioxidants, were synthesized in moderate yield (Figure 1) for covalent attachment to LEP via a hydrophobic linker, dodecanedioic acid. Tris(2-(hydroxymethyl)phenol) conjugates of LEP (2a-e) with optimal hydrophobicity were synthesized to carry LEP into the cells (Figure 2). All products were purified $(\leq 95 \%)$ by a flash chromatography system (Teledyne CombiFlash ${ }^{\circledR}$ Rf-200) and the structures of all the final compounds were confirmed by ESI/TOF mass spectrometry. Since LEP was not protected, a mixture of two phenolic and alcoholic esters was expected [30].

\subsection{Antiproliferative Activity of LEP-TPMs 2a-e}

LEP, TPMs 1a-e and LEP-TPMs 2a-e did not show significant toxicity in BT-549, PC3, A549 and 3T3-L1 cells at a concentration of $100 \mu \mathrm{M}$ after different incubation times up to $72 \mathrm{~h}$. Thus, non-cytotoxic concentrations of $5-100 \mu \mathrm{M}$ were selected for cell-based studies of LEP-TPMs $2 \mathrm{a}-\mathrm{e}$ and the physical mixture of TPMs 1a-e + LEP. The activity of compounds on the cell proliferation of the cancer cells, BT-549, PC3, A549 and 3T3-L1 was investigated for up to 72 hours at the concentration of 5-100 $\mu \mathrm{M}$. The activity of synthesized compounds 2a-e was evaluated in a comparative study with the physical mixtures of (TPMs 1a-e + LEP) and LEP alone (Figure 3).

LEP-TPMs 2a-e exhibited higher antiproliferative activity than LEP alone in all cells lines with the highest activity observed $2 \mathrm{e}$. The effect of compounds was found to be time-dependent (data were not shown). The cell proliferation inhibitory activity of compounds enhanced at a longer incubation period of compounds 


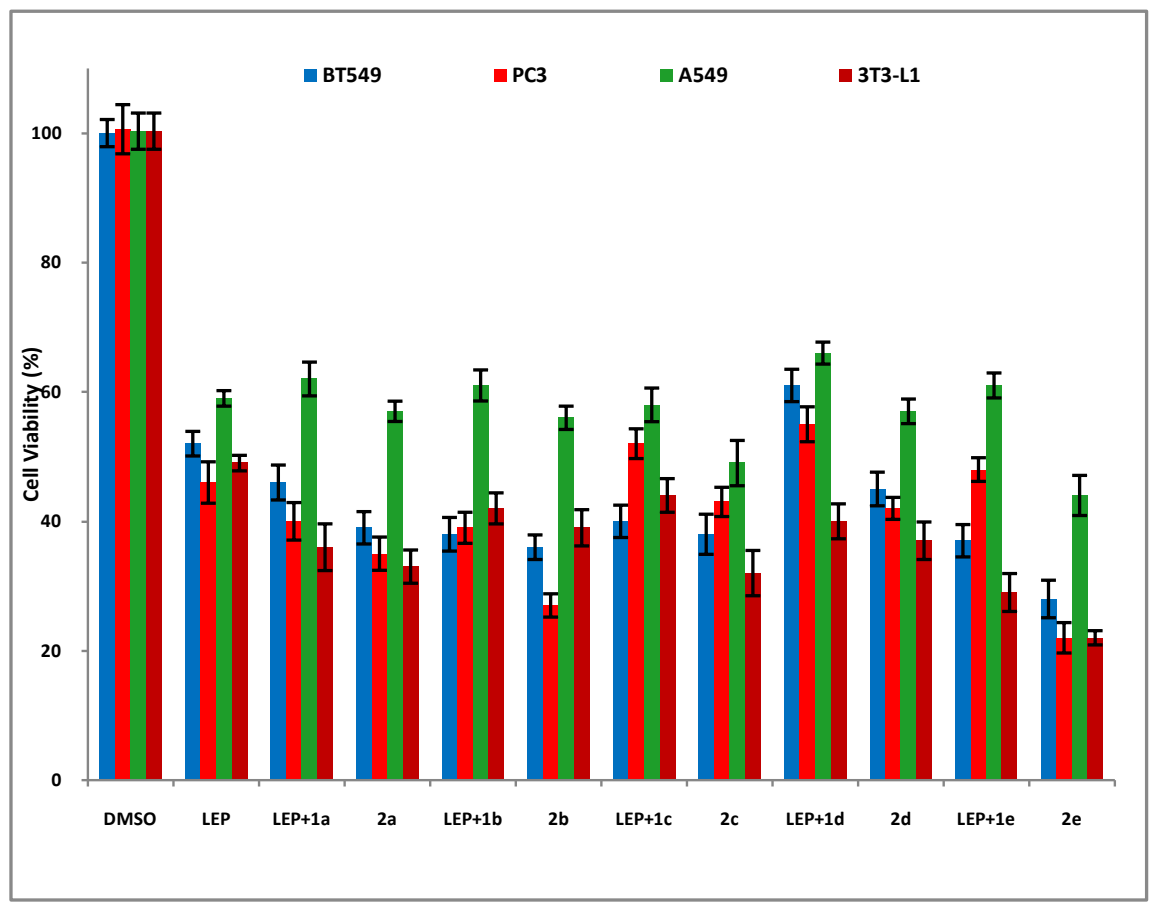

Figure 3. Inhibition of BT-549, PC3, A549 and s3T3-L1 cells by compounds (100 $\mu$ M) after $24 \mathrm{~h}$ incubation. The results are shown as the percentage of the control DMSO that has no compound (set at $100 \%)$. All the experiments were performed in triplicate $( \pm S D)$.

with cells presumably because of the higher cellular uptake. The derivatives 2a-e inhibited the cell proliferation of BT-549 (22\% - 73\%), PC3 (32\% - 78\%), A549 $(28 \%-69 \%)$ and 3T3-L1 (38\% - 72\%) at a concentration of $5-100 \mu \mathrm{M}$ after 24 $h$. These data suggest that covalent conjugation of LEP-TPMs provided a more effective transporter for LEP. The antiproliferative activity of LEP-TPMs 2a-e was in the order of PC3 > BT-549 > 3T3-L1 > A549. In general, the physical mixtures of TPMs 1a-e + LEP showed less antiproliferative activity after 24 hours against BT-549 (7\% - 23\%), PC3 (21\% - 48\%), A549 (21\%-43\%) and 3T3-L1 (26\% - 42\%) in comparison to covalent LEP-TPMs 2a-e. LEP exhibited similar antiproliferative activity in comparison to the physical mixture against tested cell lines after $24 \mathrm{~h}$ of incubation.

Cell viability was then determined by measuring the fluorescence intensity of the product using a microplate spectrophotometer. The percentage of cell survival was calculated as OD value of cells treated with the test mixture of compounds as OD value of culture medium/(OD value of control cells-OD value of culture medium) $\times 100 \%$. These data indicate that conjugation of the LEP with TPMs in compounds $\mathbf{2 a}$-e significantly improved the antiproliferative activity in tested cell lines when compared with LEP and the corresponding physical mixtures. Furthermore, the compounds were also potent against 3T3-L1 cells. The mechanism of higher antiproliferative activity of these ester conjugates was presumably because of the higher cellular uptake of the TPM analogs and/or LEP since LEP alone and the corresponding physical mixture showed significantly 
less antiproliferative activity than the corresponding LEP-TPM conjugates.

\subsection{Flow Cytometry}

The analysis showed 3.1 - 3.7 folds higher cellular uptake of LEP-TPMs than LEP alone and the physical mixtures in PC3 cells after $24 \mathrm{~h}$ incubation. The conjugate exhibited nuclear localization and retention after 24 hours, and underwent intracellular hydrolysis to LEP in PC3 cells.

\section{Conclusion}

In summary, LEP-TPMs derivatives were synthesized as prodrugs, evaluated for their activities against three cancer cell lines and one obese cell line and compared with the corresponding physical mixtures. The conjugation of LEP with a specific TPMs derivative improved the antiproliferative activity compared to the corresponding physical mixtures and LEP in all tested cell lines suggesting being a potential prodrug for delivery of the drug.

\section{Acknowledgements}

We acknowledge the financial support from the National Cancer Institute, MMC-Vanderbilt-TSU Partners in Eliminating Cancer Disparities (MVTCP), Grant Number 5U54CA163066-03. We also acknowledge the financial support from the USDA National Institute of Food and Agriculture, Grant\# TENX-1608-FS. We thank US Department of Education, Title III Part B, grant number P031B090214 for partial financial support. Jawzah Alnakhli and Samiyah Alhamed acknowledge the scholarship provided by the Saudi Arabian Cultural Mission to the US (SACM).

\section{Conflicts of Interest}

The authors declare no conflicts of interest regarding the publication of this paper.

\section{References}

[1] Thurston, B.R. (2006) Chemistry and Pharmacology of Anticancer Drugs. CRC Press, Boca Raton, 139-151.

[2] Ibsen, S., Zahavy, E., Wrasdilo, W., Berns, M., Chan, M. and Esener, S. (2010) A Novel Doxorubicin Prodrug with Controllable Photolysis Activation for Cancer Chemotherapy. Pharmaceutical Research, 27, 1848-1860. https://doi.org/10.1007/s11095-010-0183-X

[3] Chhikara, B.S. and Parang, K. (2010) Development of Cytarabine Prodrugs and Delivery Systems for Leukemia Treatment. Expert Opinion on Drug Delivery, 7, 1399-1414. https://doi.org/10.1517/17425247.2010.527330

[4] Li, X., Zhi, Q., Yao, Z., Liu, Z. and Wu, L. (2016) Pegylated Leuprorelin. CN 105237762A. 2016-01-13.

[5] Wang, Y., Li, L., Jiang, W., Yang, Z. and Zhang, Z. (2006) Synthesis and Preliminary Antitumor Activity Evaluation of a DHA and Doxorubicin Conjugate. Bioorganic \& 
Medicinal Chemistry Letters, 16, 2974-2977. https://doi.org/10.1016/j.bmcl.2006.02.066

[6] Kumar, S.A., Peter, Y.A. and Nadeau, J.L. (2008) Facile Biosynthesis, Separation and Conjugation of Gold Nanoparticles to Doxorubicin. Nanotechnology, 19, 495-501. https://doi.org/10.1088/0957-4484/19/49/495101

[7] You, J., Zhang, G. and Li, C. (2010) Exceptionally High Payload of Doxorubicin in Hollow Gold Nanosphere for Near-Infrared Light Triggered Drug Release. ACS Nano, 4, 1033-1041. https://doi.org/10.1021/nn901181c

[8] Massing, U. and Fuxius, S. (2000) Liposomal Formulations of Anticancer Agents: Selectivity and Effectiveness. Drug Resistance Updates, 3, 171-177.

https://doi.org/10.1054/drup.2000.0138

[9] Derossi, D., Joliot, A.H., Chassaing, G. and Prochiantz, A. (1994) The Third Helix of the Antennapedia Homeodomain Translocates through Biological Membranes. The Journal of Biological Chemistry, 269, 10444-10450.

[10] Derossi, D., Chassaing, G. and Prochiantz, A. (1998) Trojan Peptides: The Penetratin System for Intracellular Delivery. Trends in Cell Biology, 8, 84-87.

https://doi.org/10.1016/S0962-8924(98)80017-2

[11] Meyer-Losic, F., Quinonero, J., Dubois, V., Alluis, B., Dechambre, M., Michel, M., Cailler, F., Fernandez, A.M., Trouet, A. and Kearsey, J. (2006) Improved Therapeutic Efficacy of Doxorubicin through Conjugation with a Novel Peptide Drug Delivery Technology (Vectocell). Journal of Medicinal Chemistry, 49, 6908-6916. https://doi.org/10.1021/jm0606591

[12] Che, C., Yang, G., Thiot, C., Lacoste, M.-C., Currie, J.-C., Demeule, M., Regina, A., Beliveau, R. and Castaigne, J.-P. (2010) New Angiopep Modified Doxorubicin (ANG1007) and Etoposide (ANG1009) Chemotherapeutics with Increased Brain Penetration. Journal of Medicinal Chemistry, 53, 2814-2824. https://doi.org/10.1021/jm9016637

[13] Lindgren, M., Rosenthal-Aizman, K., Saar, K., Eiriksdottir, E., Jiang, Y., Sassian, M., Ostlund, P., Hallbrink, M. and Langel, U. (2006) Overcoming Methotrexate Resistance in Breast Cancer Tumour Cells by the Use of a New Cell-Penetrating Peptide. Biochemical Pharmacology, 71, 416-425. https://doi.org/10.1016/j.bcp.2005.10.048

[14] Amir, N.S., Rakesh, T., Bhupender, S.C., Dindyal, M. and Keykavous, P. (2013) Design and Biological Evaluation of Cell-Penetrating Peptide-Doxorubicin Conjugates as Prodrugs. Molecular Pharmaceutics, 10, 488-499. https://doi.org/10.1021/mp3004034

[15] Zhu, S., Hong, M., Zhang, L., Tang, G., Jiang, Y. and Pei, Y. (2010) PEGylated PAMAM Dendrimer-Doxorubicin Conjugates: In Vitro Evaluation and in Vivo Tumor Accumulation. Pharmaceutical Research, 27, 161-174. https://doi.org/10.1007/s11095-009-9992-1

[16] Scalbert, A., Manach, C., Morand, C. and Remesy, C. (2005) Dietary Polyphenols and the Prevention of Diseases. Critical Reviews in Food Science and Nutrition, 45, 287-306. https://doi.org/10.1080/1040869059096

[17] Spencer, J.P., Abd El Mohsen, M.M., Minihane, A.M. and Mathers, J.C. (2008) Biomarkers of the Intake of Dietary Polyphenols: Strengths, Limitations and Application in Nutrition Research. British Journal of Nutrition, 99, 12-22. https://doi.org/10.1017/S0007114507798938

[18] Bhooshan, P.K. and Rizv, S.I. (2009) Plant Polyphenols as Dietary Antioxidants in Human Health and Disease. Oxidative Medicine and Cellular Longevity, 2, 270-278. https://doi.org/10.4161/oxim.2.5.9498 
[19] Yang, C.S., Landau, J.M., Huang, M.T. and Newmark, H.L. (2001) Inhibition of Carcinogenesis by Dietary Polyphenolic Compounds. Annual Review of Nutrition, 21, 381-406. https://doi.org/10.1146/annurev.nutr.21.1.381

[20] Johnson, I.T., Williamson, G. and Musk, S.R.R. (1994) Anticarcinogenic Factors in Plant Foods: A New Class of Nutrients? Nutrition Research Reviews, 7, 175-204. https://doi.org/10.1079/NRR19940011

[21] Talalay, P., De Long, M.J. and Prochaska, H.J. (1988) Identification of a Common Chemical Signal Regulating the Induction of Enzymes That Protect against Chemical Carcinogenesis. Proceedings of the National Academy of Sciences, 85, 8261-8265. https://doi.org/10.1073/pnas.85.21.8261

[22] Khan, N. and Mukhtar, H. (2008) Multitargeted Therapy of Cancer by Green Tea Polyphenols. Cancer Letters, 269, 269-280.

https://doi.org/10.1016/j.canlet.2008.04.014

[23] Giovanni, D.P. and Franco, S. (2013) Obesity as a Major Risk Factor for Cancer. Journal of Obesity, 2013, Article ID: 291546. https://doi.org/10.1155/2013/291546

[24] Calle, E.E., Rodriguez, C., Walker-Thurmond, K. and Thun, M.J. (2003) Overweight, Obesity and Mortality from Cancer in a Prospectively Studied Cohort of U.S. Adults. JThe New England Journal of Medicine, 348, 1625-1638. https://doi.org/10.1056/NEJMoa021423

[25] Calle, E.E. and Kaaks, R. (2004) Overweight, Obesity and Cancer: Epidemiological Evidence and Proposed Mechanisms. Nature Reviews Cancer, 4, 579-591. https://doi.org/10.1038/nrc1408

[26] Renehan, A.G., Tyson, M., Egger, M., Heller, R.F. and Zwahlen, M. (2008) Body-Mass Index and Incidence of Cancer: A Systematic Review and Meta-Analysis of Prospective Observational Studies. The Lancet, 371, 569-578. https://doi.org/10.1016/S0140-6736(08)60269-X

[27] Wolin, K.Y., Carson, K. and Colditz, G.A. (2010) Obesity and Cancer. Oncologist, 15, 556-565. https://doi.org/10.1634/theoncologist.2009-0285

[28] Suja, S., Bharat Raj, B., Kyung Ja, C., Keun-Hyeung, L. and Hyeongjin, C. (2007) Methylenedisalicylic Acid Derivatives: New PTP1B Inhibitors That Confer Resistance to Diet-Induced Obesity. Bioorganic \& Medicinal Chemistry Letters, 17, 2760-2764. https://doi.org/10.1016/j.bmcl.2007.02.069

[29] Mark, C., Suseela, Erik, D.C., Dominique, S., Mark, E.G. and Julie, A.B. (1991) Synthesis and Anti-HIV Activities of Low Molecular Weight Aurintricarboxylic Acid Fragments and Related Compounds. Journal of Medicinal Chemistry, 34, 337-342. https://doi.org/10.1021/jm00105a053

[30] There is a competition between phenol and primary alcohol to form ester with the linker. The alcohol has higher nucleophilicity in this reaction condition, however its nucleophilicity hampers by higher steric hindrance. Since the phenol is not the phenolate form, it is less reactive than alcohols for nucleophilic reactions, in contrast the lower steric hindrance around the phenol increases its nucleophilicity. Therefore, a mixture of esters is expected. We were not able to separate the mixture by chromatography technique. 


\section{Abbreviations}

BT-549, human invasive ductal breast carcinoma cell line;

PC3, human prostate carcinoma cell line;

A549, human lung cancer cell line;

3T3-L1, mouse pre-adipocytes cell line;

LEP, Leuprorelin;

TPMs, Triphenylmethanols;

DCM, dichloromethane;

NMP, (N-Methyl-2-pyrrolidone);

HBTU, 2-(1 H-benzotriazol-1-yl)-1,1,3,3-tetramethyluronium hexafluorophosphate;

DIC, $N, N^{\prime}$-Diisopropylcarbodiimide;

DIPEA, $N, N$-Diisopropylethylamine;

$\mathrm{GnRH}$, gonadotropin-releasing hormone;

FSH, Follicle-stimulating hormone;

LH, Luteinizing hormone;

LHRH, luteinizing hormone-releasing hormone;

FACS, Fluorescence Activated Cell Sorter. 